\title{
IN SPONDYLOTIC CERVICAL MYELOPATHY ANTERIOR CERVICAL DISCECTOMY AND FUSION BY PEEK CAGE WITHOUT PLATE REINFORCEMENT IS A STANDARD METHOD OF TREATMENT
}

\author{
ISLAM MA ${ }^{1}$, PARVEZ $Q^{2}$, SARKER $\mathrm{SK}^{3}$, GONI MF${ }^{4}$, RANA MM ${ }^{5}$
}

\begin{abstract}
Background: Anterior cervical discectomy with fusion (ACDF) is challenging with respect to both patient selection and choice of surgical procedure.

Objective: The aim of this study was to evaluate the clinical outcome of anterior cervical discectomy and fusion with an artificial cage made of polyetheretherketone.

Patients and Methods: From January 2012 to January 2016, 40 consecutive patients referred to the Department of spine surgery, Bangabandhu Shekh Mujib Medical University were recruited for the study.Postoperative Clinical outcome assessd with Nurick scale for myelopathy, Odom's criteria for functional outcome and Visual Analogue Scale (VAS) for both neck and arm pain. Radiological fusion was assessed by X-ray. Operative complications were reported.
\end{abstract}

Results: 18 patients were operated for one level discectomy and fusion with PEEK cages and 22 patients for two levels. There were 24 (60\%) males and 16 (40\%) females. The age of the patients ranged from 30-72 years, a mean $\pm S D$ 45 \pm 8.34 . At the 2 years clinical follow-up, there were significant post operative improvements of Nurick scale, and VAS comparative to preoperative record. According to Odom's criteria, 36/40 patients (90\%) were graded excellentgood.

Conclusion: Anterior cervical discectomy and fusion with polyetheretherketone (PEEK) cage is an effective treatment of cervical myelopathy having higher fusion rate and lack of donor site morbidity.

Keyword: Anterior cervical discectomy with fusion (ACDF), polyetheretherketone (PEEK), VAS Visual analogue score.

J Dhaka Med Coll. 2016; 25(2) : 110-114

\section{Introduction}

Spinal fusion offers the surgeon an opportunity to remove the pathologic process, eliminate painful motion and obtain decompression of the neural elements. ${ }^{1}$ Fusion is at present the gold standard treatment for herniated cervical discs. Currently, over 95\% fusion rate occurs after application of anterior cervical implants ${ }^{2}$. The indications for anterior cervical discectomy fusion (ACDF) include radiculopathy, myelopathy, myelo-radiculopathy and traumatic instability involving single or multiple levels ${ }^{3}$.

There are various techniques for performing ACDF depending on surgeon preference; including the Cloward technique or discectomy and interposition graft ${ }^{4,5}$. The interposition graft used may include autologous bone,

1. Dr. Md. Anowarul Islam, Associate Professor (Spinal Surgery), Department of Orthopaedic Surgery, Bangabandhu Sheikh Mujib Medical University

2. Dr. Qamruzzaman Parvez, Resident, Spine Unit, Department of Orthopaedic Surgery, Bangabandhu Sheikh Mujib Medical Univaersity

3. Dr. S.K. Sarker, Resident, Spine Unit, Department of Orthopaedic Surgery, Bangabandhu Sheikh Mujib Medical University

4. Dr. Md. Fahad Goni, Resident, Spine Unit, Department of Orthopaedic Surgery, Bangabandhu Sheikh Mujib Medical University

5. Dr. Md. Masud Rana, Resident, Spine Unit, Department of Orthopaedic Surgery, Bangabandhu Sheikh Mujib Medical University

Correspondence: Dr. Md. Anowarul Islam Associate Professor, Spinal Surgery, Department of Orthopaedic Surgery, Bangabandhu Sheikh Mujib Medical University. E-mail: maislam.spine@gmail.com, Phone no.+8801819506648 
allograft, and synthetic material or cages. Cervical cages of different materials have been used as titanium, Polyetheretherketone (PEEK) and carbon fiber ${ }^{6}$. Different fusion materials have been used too, as iliac crest autograft ${ }^{6}$, allograft ${ }^{2}$, demeneralized bone matrix ${ }^{7}$, hydroxyapatite ${ }^{8}$, and bone morphogenetic proteins ${ }^{9}$. There are different complications of using graft alone; graft collapse, extrusion, and pseudarthrosis ${ }^{6}$.

In this study, we try to evaluate single or double level ACDF with PEEK Cages without plate. We have seen sagittal alignment, cervical lordosis, graft subsidence, fusion rate and adjacent-level ossification.

\section{Patients and Methods}

From January 2012 to January 2016, 40 consecutive patients referred to the Department of spine surgery, Bangabandhu Shekh Mujib Medical University were recruited for the study. The duration of preoperative symptoms ranged from 2 months up to one year on conservative management including medical treatment and physiotherapy.

The parameters registered the day before surgery included age, sex, symptom duration before surgery (months), previous history of cervical discectomy, previous neck trauma, working status, radicular and neck pain, myelopathy and paresis. The pain category was scored using a VAS ${ }^{\mathbf{1 0}}$. Nurick scale was used for myelopathy ${ }^{\mathbf{1 1}}$; pre-operative and postoperative Odom's criteria for functional outcome ${ }^{\mathbf{1 2}}$.

Nurick Scale: A six grade system (0-5) based on the 'difficulty in walking'.

\section{Grade Description:}

0 Signs or symptoms of root involvement but without evidence of spinal cord disease.

1 Signs of spinal cord disease but no difficulty in Walking.

2 Slight difficulty in walking which does not prevent full-time employment.

3 Difficulty in walking which prevented full time employment or the ability to do all housework, but which was not so severe as to require someone else's help to walk.
4 Able to walk only with someone else's help or with the aid of a frame.

5 Chair bound or bedridden

Odom's criteria for Outcome evaluation

Excellent: All pre-operative symptoms relieved, abnormal findings improved

Good: Minimal persistence of pre-operative symptoms, abnormal findings unchanged or improved.

Fair: Definite relief of some pre-operative symptoms, other symptoms unchanged or slightly improved .

Poor: Symptoms and signs unchanged or worse.

Patient with cervical recurrent disc, trauma, neoplasia, and infection excluded from the study. Diagnostic work-up: Cervical MRI, cervical X-ray, and some cases needed CT cervical spine with sagittal reconstruction. The patient followed-up clinically and radiologicaly at 6,12, and 24 months. Surgery-related complications were reported.

\section{Results}

The study included 40 patients. Eighteen patients were operated for one level discectomy and fusion with PEEK cages and 22 patients for two levels. There were $24(60 \%)$ males and $16(40 \%)$ females. The age of the patients ranged from $30-72$ years, a mean \pm SD $45 \pm 8.34$. There were $10(25 \%)$ smokers.

There were 12 patients $(30 \%)$ with radiculopathy, 10 patients (25\%) with myelopathy, and 18 patients $(45 \%)$ with radiculomyelopathy. Regarding the levels operated, there were 14 C3-4 levels, 18 C4-5 levels, 26 C5-6 levels, and 4 C6-7 levels. The total levels done were 62 levels. Duration of symptoms ranged from 1.5 months to 12 months; mean \pm SD was $8 \pm 3.23$ months. Patients were followed-up for a period of 6 months to 24 months, mean \pm SD 10.3 \pm 3.4 months.

At the 2 years follow-up, we reported a significant post operative improvement of Nurick scale and VAS for arm and neck pain comparative to preoperative record. According to Odom criteria, 36/40 patients $(90 \%)$ were graded excellent-good. No patient as graded poor. 
There were some transient complications- dysphagia is reported in 5 patients $(12.5 \%)$ and im-proved within the first 2 weeks, superficial wound infection reported in 2 patients $(5 \%)$ and transient vocal cord dysfunction in one case.

Cage subsidence of $3 \mathrm{~mm}$ occurred in 3 cases $(7.5 \%)$ and $5 / 62(8 \%)$ segments. The loss of segmental lordosis from immediately after surgery to the last follow-up $3^{\circ}$ in $14 / 62$ segments

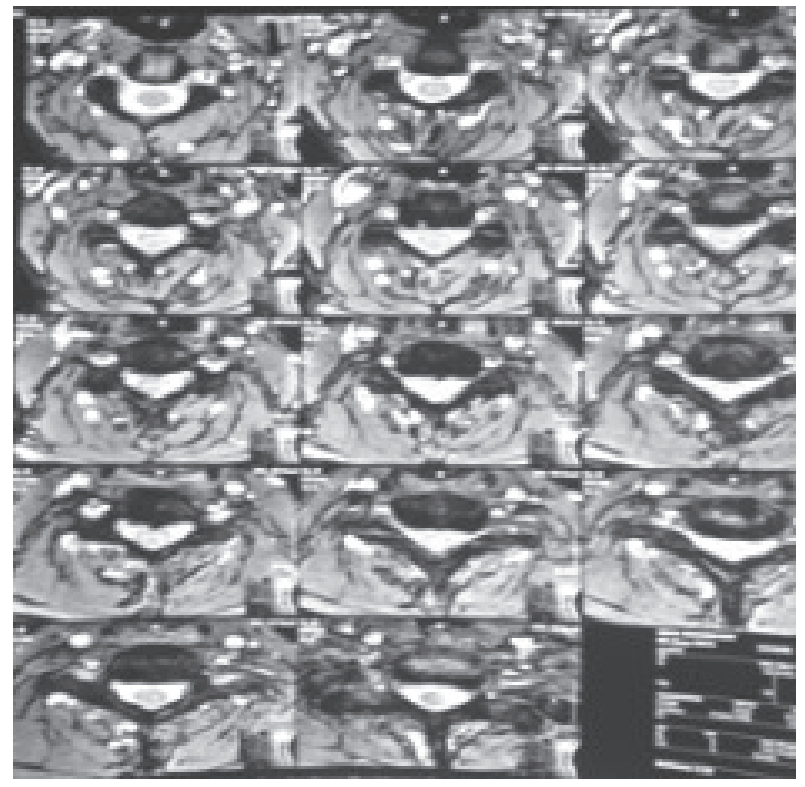

Fig.-1: Preoperative MRI axial view

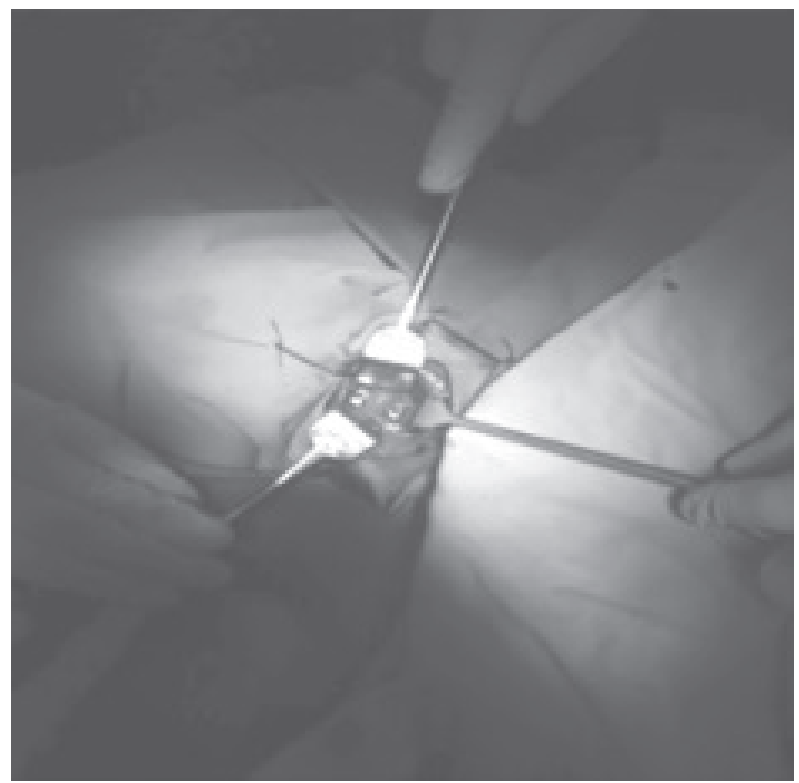

Fig.-3: intraoperative cage placement
$(22.5 \%)$ while $77.5 \%$ shows no progression of angle after fusion. All cases of subsidence occurred in the lower anterior end plate. Fusion occurred in 36/40 (90\%). The average age of the non fusion group of the whole series (4 patients) was older $48.8 \pm 4.3$. There were 10 smokers at the study, 7 of them were at the fusion group. At the non fusion group, all patients complain of chronic neck pain that mandate analgesic.

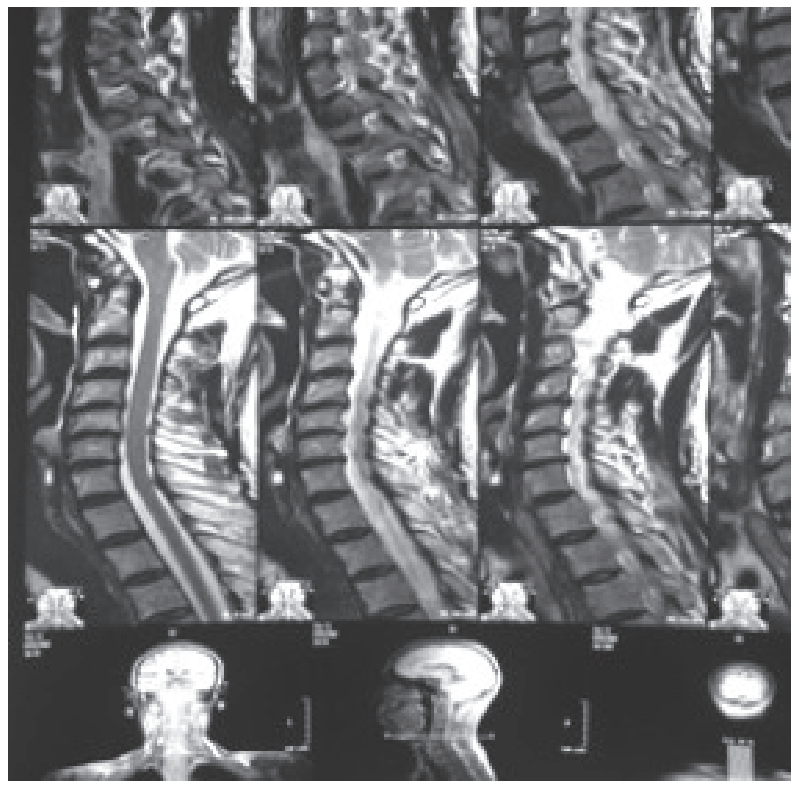

Fig.-2: preoperative MRI sagital view

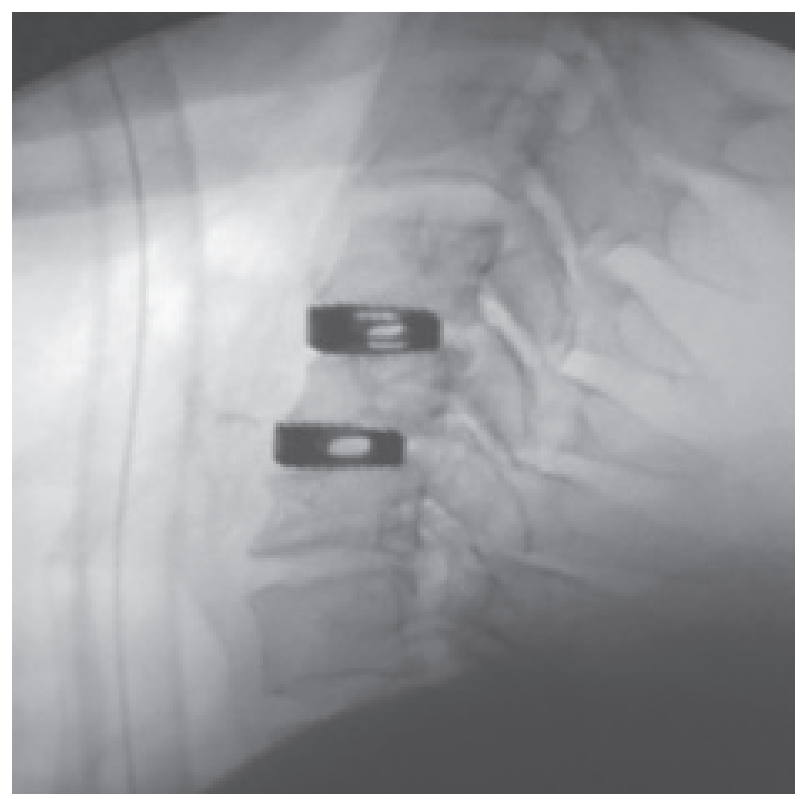

Fig.-4: postoperative $X$-ray cervical spine 


\section{Discussion}

Fusion is usually carried out with an intervertebral bone graft to restore disc height and to ensure primary stability of the motion segment. Discectomy alone may lead to poor clinical results due to loss of disc height, narrowing of the neural foramen and to malalignment of the cervical spine because of the resulting kyphosis of the motion segment ${ }^{13,14}$.

A fusion cage not only ensure primary stability between the vertebrae but also allow bone ingrowth to achieve secondary stability without losing the structural integrity of the segment [15]. In this study, fusion occurred in 36/40 patients $(90 \%)$. It has been reported that the cage achieves excellent fusion rates ranging from $93.1-100 \%{ }^{7,16,17,18,19}$.

Cage sub-sidence of $3 \mathrm{~mm}$ occurred in 3 cases $(7.5 \%)$ and $5 / 62(8 \%)$ segments in this study. Although it doesn't affect fusion, it affects mainly segmental lordosis. Bartels et al. [20] showed the same incidence.

Anterior cervical decompression and fusion with autologous bone graft has been the standard treatment for cervical discectomy for more than 50 years ${ }^{19}$. The literature also reports a consistent rate of $1-12 \%$ non-fusion for single-level anterior discectomy and autogenous bone fusion, $20-27 \%$ for two-level, and approximately $30-56 \%$ for three-level fusions ${ }^{17,18}$. That's why plate fixation has been added for adequate fusion ${ }^{3}$.

However, Connolly et al. ${ }^{[21]}$ reported that plate fixation does not enhance fusion rate nor does it improve clinical outcome in one and two level ACDF.

Using a fusion cage without fixation, Hacker et al. ${ }^{22}$ compared to ACDF with bone graft and plate fixation in a multi-center randomized study including both one- and two-level degenerative disc disease with radiculopathy but found no significant difference in clinical outcome between the two groups. For multilevel, fusion rates are superior in the plated group (99\%) than nonplated group (93\%). In addition fusion is at a faster rate ${ }^{3}$. However, plating has complications. Plate complication rate varies from $2.2-24.0 \%{ }^{[17]}$ and includes screw pullout, screw breakage, injury of the laryngeal nerve, injury of esophagus, injury of spinal cord or root, injury of vertebral artery, and wound infection. Additionally, the operative time is usually longer, and more cost to patient or health authority.

This study found, with others [19], that fusion is higher in PEEK group, clinical outcome for radicular pain is significantly better. Due to donor site morbidity, and relatively shorter operation time, and nearly the equivalent clinical results between cage and bone graft, many authors prefer cages for this type of fusion to bone graft $6,7,15,19$.

According to the previous data, and based on the current literature, cage fusion (both singlelevel and two-level ) however, probably provide favorable clinical outcomes for brachialgia and no donor site complications but surgeon should follow guideline to avoid subsidence and its sequelae.

\section{Conclusion:}

Anterior cervical discectomy and fusion with PEEK cage is considered ideal for treating cervical disc disease with radicular pain and myleopahty in terms of clinical improvement, restoration of cervical lordosis, bone fusion and in long term follow-up. PEEK cage had some favorable clinical outcome and high fusion rate but lack of donor site morbidity.

\section{References}

1. HILIBRAND A.S. and ROBBINS M.: Adjacent segment degeneration and adjacent segment disease: The consequences of spinal fusion. Spine. J., 4: 190S-194S, 2004.

2. MUMMANENI P.V., BURKUS J.K., HAID R.W., TRAYNELIS V.C. and ZDEBLICK T.A.: Clinical and radiographic analysis of cervical disc arthroplasty com-pared with allograft fusion: A randomized controlled clinical tria. J. Neurosurg. Spine, 6: 198-209.

3. MOBBS R.J., RAO P. and CHANDRAN N.K.: Anterior cervical discectomy and fusion: Analysis of surgical outcome with and without plating. J. Clin. Neurosci., 14: 639-642, 2007.

4. CLOWARD R.B.: The anterior approach for removal of ruptured cervical disc. J. Neurosurg., 15: 602-617, 1956. 
5. ARONSON N.I.: The management of soft cervical disc protrusions using the Smith-Robinson approach. Clin. Neurosurg., 20: 253-258, 1973.

6. CHOU Y.C., CHEN D.C., HSIEH W.A., CHEN W.F., YEN P.S., HARNOD T., CHIOU T.L., CHANG Y.L., SU C.F., LIN S.Z. and CHEN S.Y.: Efficacy of anterior cervical fusion: Comparison of titanium cages, polyethere-therketone (PEEK) cages and autogenous bone grafts. J. Clin. Neurosci., 15: 1240-1245, 2008.

7. TOPUZ K., COLAK A., KAYA S., SIM5EK H., KUTLAY M., DEMIRCAN M.N. and VELIOCLU M.: Twolevel contiguous cervical disc disease treated with peek cages packed with demineralized bone matrix: Results of 3-year follow-up. Eur. Spine. J., 18: 238-243, 2009.

8. KIM S.C., KANG S.W., KIM S.H., CHO K.H. and KIM S.H.: Clinical and radiological outcomes of anterior cervical interbody fusion using hydroxyapatite spacer. J. Korean. Neurosurg. Soc., 46: 300-304, 2009.

9. HAU A.M.T. and MOBBS: Bone graft substitutes in anterior cervical discectomy and fusion. C. Eur. Spine J., 18: 449-464, 2009. 10-HUSKISSON EC: Measurement of pain. J. Rheumatol., 9: 768-769, 1982.

10. HUSKISSON EC: Measurement of pain. J. Rheumatol., 9: 768-769, 1982.

11. NURICK: The pathogenesis of the spinal cord disorder associated with cervical spondylosis. Brain, 95: 87-100, 1972.

12. ODOM G.L., FINNEY W. and WOODHALL B.: Cervical disc lesions. JAMA, 166: 23-28, 1958.

13. DAN N.G.: Spinal angulation after anterior discectomy and graftless fusion. J. Clin. Neurosci., 7: 124, 2000.

14. SAVOLAINEN S., RINNE J. and HERNESNIEMI J.: A prospective randomized study of anterior single-level cervical disc options with long-term follow-up: Surgical fusion is unnecessary. Neurosurgery, 1: 51-55, 1998.

15. LIND B., ZOEGA B. and ROSEN H.: Autograft versus interbody fusion cage without plate fixation in the cervical spine: A randomized clinical study using radiostereometry. Eur. Spine J., 16: 12511256, 2007.

16. GERCEK E., ARLET V., DELISLE J. and MARCHESI D.: Subsidence of stand-alone cervical cages in anterior interbody fusion: Warning. Eur. Spine J., 12: 513-516, 2003.

17. DEMIRCAN M.N., KUTLAY A.M., COLAK A., KAYA S., TEKIN T., KIBICI K. and UNGOREN K.: Multilevel cervical fusion without plates, screws or autogenous iliac crest bone graft. J. Clin. Neurosci., 14: 723-728, 2007.

18. ECK K.R., LENKE L.G., BRIDWELL K.H., GILULA L.A., LASHGARI C.J. and RIEW K.D.: Radiographic assessment of anterior titanium mesh cages. J. Spinal. Disord, 13: 501-510, 2000.

19. LIED B., ROENNING P., SUNDSETH J. and HELSETH E.: Anterior cervical discectomy with fusioin patient with cervical degeneration a prospective outcome study of 258 patients (181fused with autologous bone graft and 77 fused with a PEEK cage. BMC Surgery, 10: 1-9, 2010.

20. BARTELS R.H., DONK R.D. and FEUTH T.: Subsidence of stand-alone cervical carbon fiber cages. Neurosurgery, 58: 502-508, 2006.

21. CONNOLLY P.J., ESSES S.I. and KOSTUIKJ.P.: Anterior cervical fusion: Outcome analysis of patients fused with and without anterior cervical plates. J. Spinal Disord, 9: 202-206, 1996.

22. Hacker RJ, Cauthen JC, Gilbert TJ, Griffith SL. A prospective randomized multicenter clinical evaluation of an anterior cervical fusion cage. Spine, 20: 2646-2654, 200. 